\title{
Modeling of High-Energy Pulsed Laser Interactions with Coupons
}

\author{
C.D. Boley, A.M. Rubenchik
}

February 6, 2003

U.S. Department of Energy

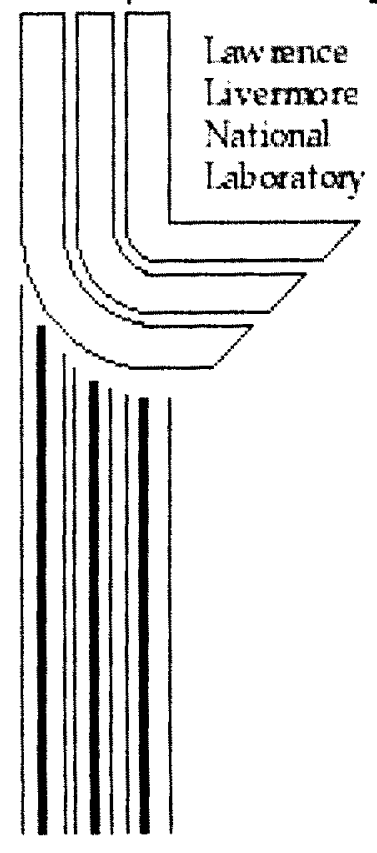




\section{DISCLAIMER}

This document was prepared as an account of work sponsored by an agency of the United States Government. Neither the United States Government nor the University of California nor any of their employees, makes any warranty, express or implied, or assumes any legal liability or responsibility for the accuracy, completeness, or usefulness of any information, apparatus, product, or process disclosed, or represents that its use would not infringe privately owned rights. Reference herein to any specific commercial product, process, or service by trade name, trademark, manufacturer, or otherwise, does not necessarily constitute or imply its endorsement, recommendation, or favoring by the United States Government or the University of California. The views and opinions of authors expressed herein do not necessarily state or reflect those of the United States Government or the University of California, and shall not be used for advertising or product endorsement purposes.

This work was performed under the auspices of the U. S. Department of Energy by the University of California, Lawrence Livermore National Laboratory under Contract No. W-7405-Eng-48.

This report has been reproduced directly from the best available copy.

Available electronically at http://www.doc.gov/bridge

Available for a processing fee to U.S. Department of Energy

And its contractors in paper from

U.S. Department of Energy

Office of Scientific and Technical Information

P.O. Box 62

Oak Ridge, TN 37831-0062

Telephone: (865) 576-8401

Facsimile: (865) 576-5728

E-mail: reports@adonis.osti.gov

Available for the sale to the public from

U.S. Department of Commerce

National Technical Information Service

5285 Port Royal Road

Springfield, VA 22161

Telephone: (800) 553-6847

Facsimile: (703) 605-6900

E-mail: orders@ntis.fedworld.gov

Online ordering: http://www.ntis.gov/ordering.htm

OR

Lawrence Livermore National Laboratory

Technical Information Department's Digital Library

http://www.llnl.gov/tid/Library.html 


\title{
Modeling of High-Energy Pulsed Laser Interactions with Coupons
}

\author{
C. D. Boley and A. M. Rubenchik
}

\begin{abstract}
We describe a computational model of laser-materials interactions in the regime accessed by the solid state heat capacity lasers (SSHCLs) built at LLNL. We show that its predictions compare quite favorably with coupon experiments by the $10 \mathrm{~kW}$ SSHCL at LLNL.
\end{abstract}

\section{Introduction}

The development of a computational model of material interactions produced by solid state heat capacity lasers has been an area of intense activity. In this report, we describe such a model and discuss its application to coupon experiments with the $10 \mathrm{~kW}$ SSHCL. The experiments were performed at the High Energy Laser Systems Test Facility (HELSTF) at White Sands Missile Range. The laser produced pulses of high energy (at least $500 \mathrm{~J}$ ) and long pulse length (hundreds of microseconds), at $20 \mathrm{~Hz}$. Typical fluences on target ranged up to $1500 \mathrm{~J} / \mathrm{cm}^{2}$ per pulse, with peak intensities in the range of $1-10 \mathrm{MW} / \mathrm{cm}^{2}$.

The experiments tested the capabilities of the laser for material removal and coupon melt-through. They were conducted both in ambient air and in the presence of Mach flow. The model generally showed quite favorable agreement with experiment. From the dependence on the material data, the model also indicated how a pulsed laser could achieve better energy deposition in this regime than a continuous (CW) counterpart.

The body of this paper describes the following topics, listed by section number:

(2) model in quiescent air,

(3) comparison with experiments in quiescent air,

(4) effects of air flow,

(5) comparison with experiments involving air flow,

(6) importance of material properties,

(7) advantage of pulsed lasers over CW lasers,

(8) conclusions and recommendations.

\section{Model in quiescent air}

First it is advantageous to note some phenomenology from the HELSTF experiments. Figure 1 shows dramatic streaks of ejected material, the visible radiation from which corresponds to a temperature of several thousand degrees. Simple estimates suggest that these are ejected liquid blobs heated during passage through the beam. (This shot is without air flow, which sweeps away the smaller blobs, as quantified later.) Also shown in Fig. 1 is the pattern of ejected metal remaining on an aluminum coupon after a few shots. The frozen lips on the sides of the holes again point to liquid ejection. Thus we expect liquid hydrodynamics to play a key role in the physics. In addition, if we estimate the maximum material removed by vaporization alone, we have

$$
\Delta z \approx \alpha F / \rho H_{v}
$$

where $\alpha$ is the typical absorptivity, $F$ is the fluence, and $H_{v}$ is the heat of vaporization. This shows that vaporization can account for only a fraction, of order $30 \%$, of the observed material removal. Nevertheless, vaporization is not negligible. In addition, as seen below, it provides the recoil force for liquid expulsion. Therefore the model must describe the hydrodynamics of both liquid and vapor. Other important effects are heat transport in the solid and the interaction with the surrounding air. 

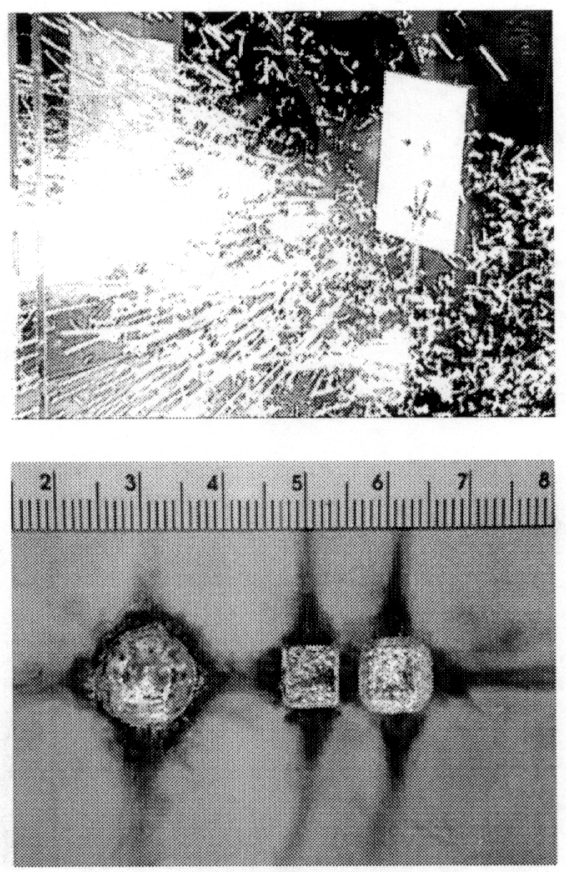

Fig. 1. Above: streaks emanating from a coupon during SSHCL shot without air flow. Below: sample debris patterns in an aluminum target.
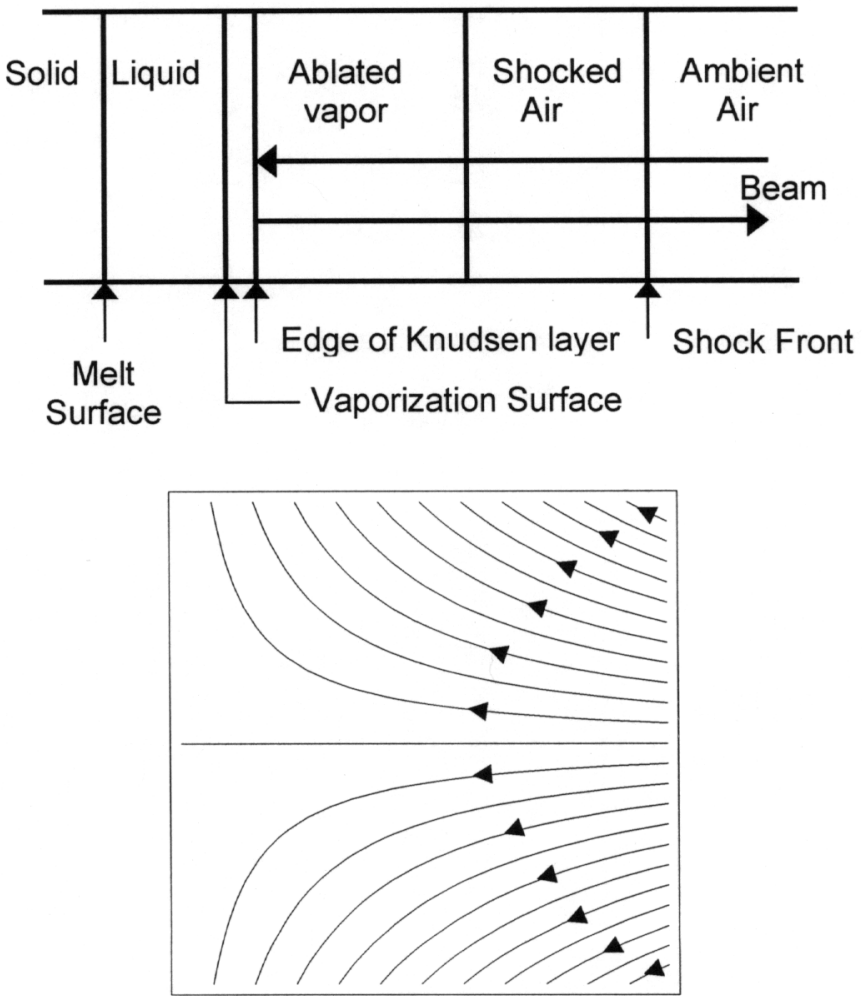

Fig. 2. Above: geometry of the model (not to scale). Below: streamlines in the liquid. The melt line is at the left, and the liquid surface is at the right. 
For these purposes, we have used a computational model, called THALES, which has been developed intermittently over the past several years. It was first used, in a less advanced form, to model drilling by copper vapor lasers [1]. Later, it was used to model vaporization in beam dumps for a high-power laser [2]. These applications were at a sufficiently high intensity that material removal occurred via vaporization alone. The first use of the code to model SSHCLs was reported in [3]. Recently, we presented new capabilities of the model and selected results at a meeting [4] and at a workshop [5]. The new features include liquid hydrodynamics and some important effects of air flow.

The basic model is in one dimension, while the liquid hydrodynamics is handled in two dimensions. The geometry of the model, in the absence of air flow, is shown in Fig. 2. From left to right, the model describes heat conduction in the solid, a moving melt line, heat conduction and liquid motion in the melt, a moving ablation surface, a thin Knudsen layer of molecular flow [6], the hydrodynamically expanding vapor, a moving vapor/air boundary, the hydrodynamically expanding air, and a shock front. Reasonable estimates for temperature-dependent material properties (primarily the thermal conductivity and the material absorptivity) are employed, as discussed in Sec. 6. Since typical vapor temperatures are only a few thousand degrees, absorption in the vapor is negligible. In reality, absorption may occur in the ejected liquid blobs, but this is not considered here. In the presence of air flow, as noted later, the smaller blobs are swept away.

In the liquid model, the fluid is pushed inward (to the left) and toward the radial edges by the recoil pressure of the ablated vapor, as shown by the streamlines in Fig. 2. The fluid reaching the edges is assumed to be removed from the system. This picture is embodied in the following solution for $2 \mathrm{D}$ incompressible, potential flow [7]:

$$
v_{z}(z, t)=-2 \beta(t)\left[z-z_{m}(t)\right], \quad v_{r}(r, t)=\beta(t) r
$$

where $\mathrm{z}$ is to the right in the figure and $z_{m}(t)$ is the position of the melt surface. The function $\beta(t)$ responds to the central pressure just beneath the surface via

$$
d \beta / d t+\beta^{2}=\left(2 / \rho a^{2}\right) p_{0}(t)
$$

where $\rho$ is the (constant) liquid density and $a$ is the beam radius. Since the model does not describe the flow up the edges, it is most appropriate for shallow holes, such as those considered here.

\section{Comparison with experiments in quiescent air}

Now we turn to simulations of coupon experiments with the $10 \mathrm{~kW}$ SSHCL at HELSTF, first considering experiments in quiescent air. The pulse form used in the simulations is shown in Fig. 3. It has a FWHM of about $300 \mu \mathrm{s}$. In some experiments, it is stretched to about $680 \mu \mathrm{s}$ by appropriate phasing of the flashlamps. Note the narrow initial spike, which rises to a peak intensity about an order of magnitude higher than that of the main part of the pulse. It accounts for about $5 \%$ of the pulse energy. Because of the multimode structure of the beam, the spatial profile is practically flat.

To illustrate the effects of liquid ejection, let us consider a pulse of about $470 \mathrm{~J}$, with spot size $0.77 \mathrm{~cm}^{2}$ (corresponding to a fluence about $610 \mathrm{~J} / \mathrm{cm}^{2}$ ), on a steel coupon. The calculated phase divisions within the coupon (i.e. regions of solid, liquid, and vapor), as functions of time, are shown in Fig. 4. The left-hand plot refers to a simulation without liquid motion. Here a melt layer of maximum depth about $60 \mu \mathrm{m}$ opens up and then closes at about $1.5 \mathrm{~ms}$. About $25 \mu \mathrm{m}$ of material are removed, by vaporization. The right- 


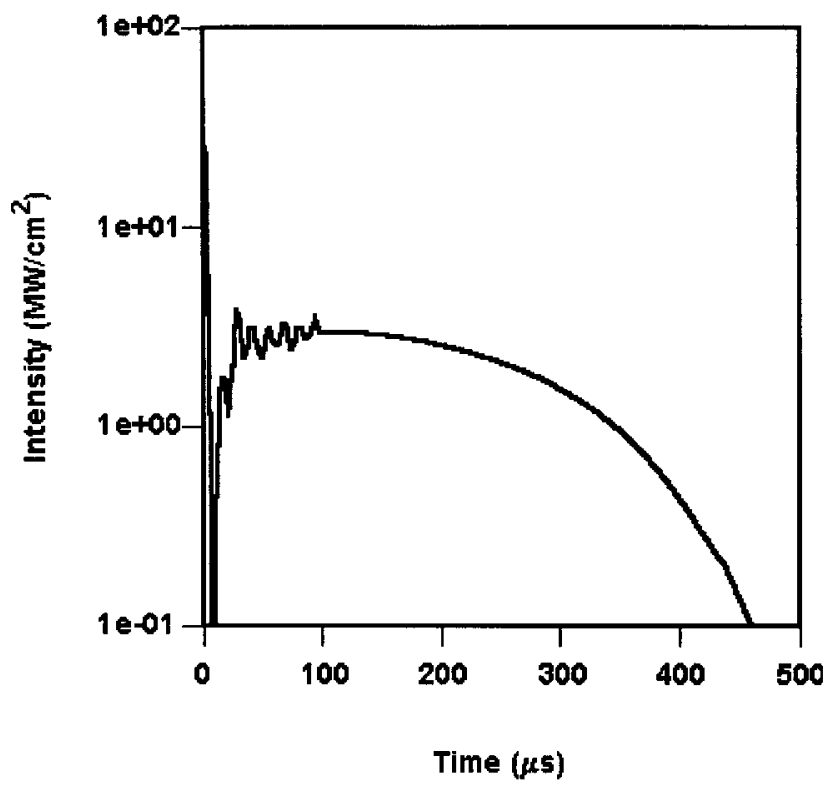

Fig. 3. Pulse shape of $10 \mathrm{~kW}$ SSHCL. The intensity corresponds to a fluence of $900 \mathrm{~J} / \mathrm{cm}^{2}$.
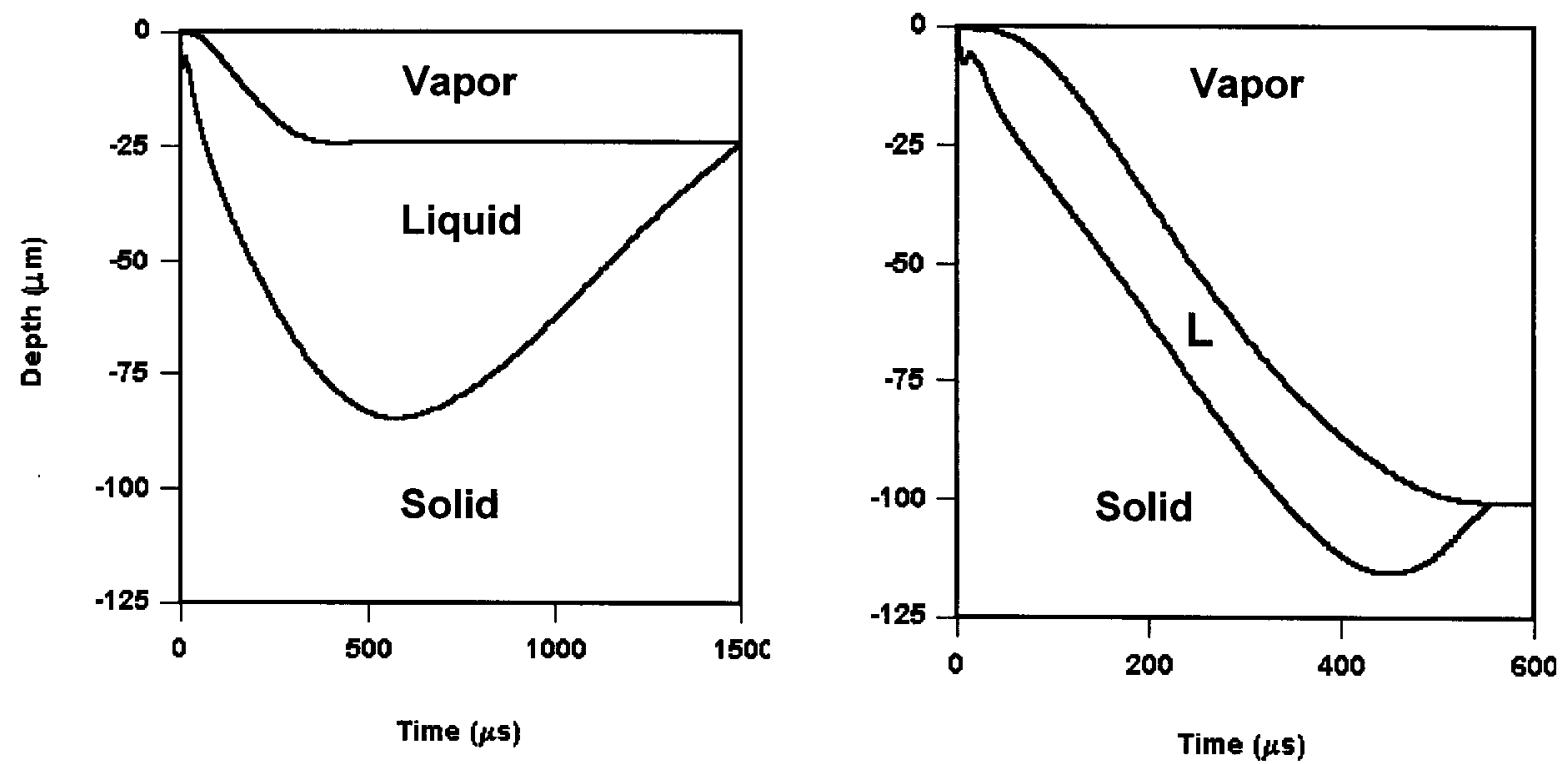

Fig. 4. Model predictions of phase divisions in coupon without liquid hydrodynamics (left) and with liquid hydrodynamics (right). 

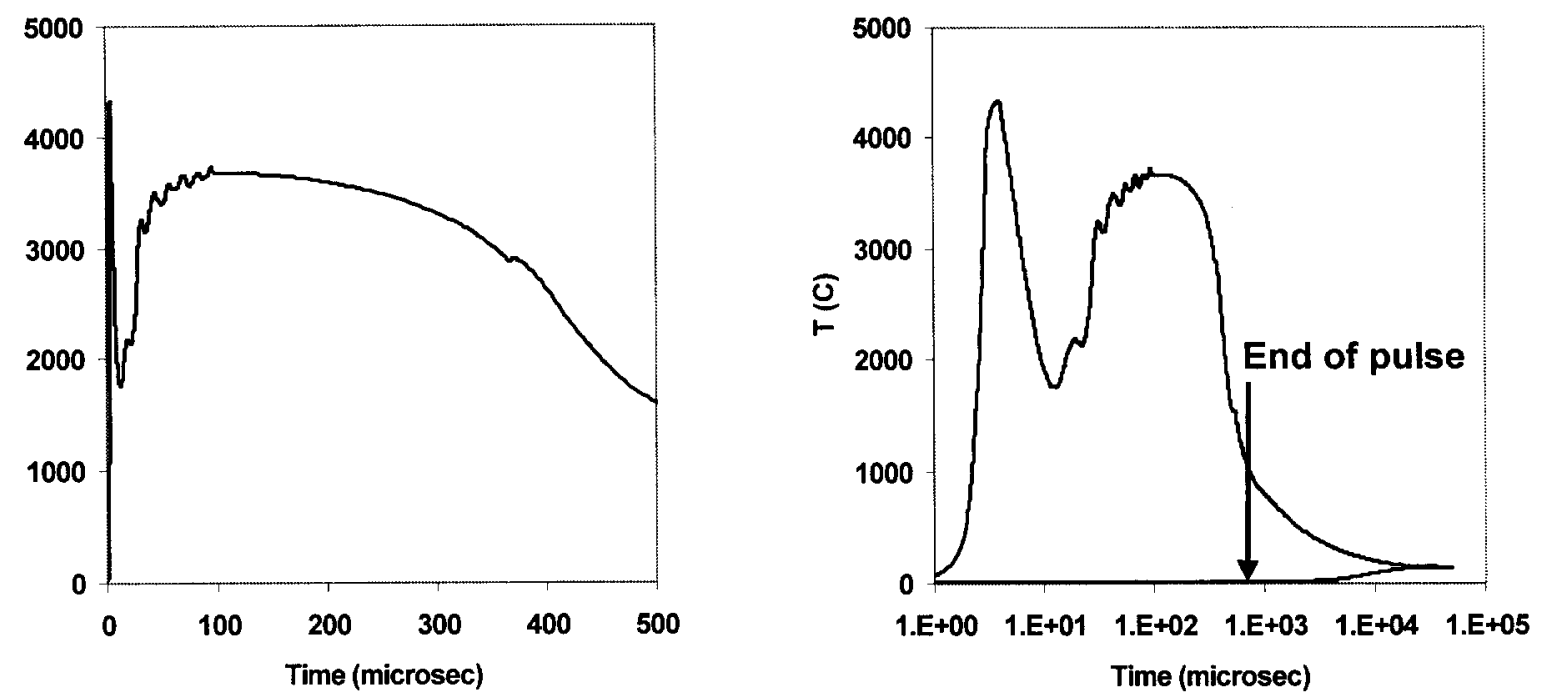

Fig. 5. Calculated temperature of the heated edge, for the second case of the previous figure. The plots give a short, linear time scale and a longer, logarithmic time scale. In the right-hand plot, the increasing line near $10 \mathrm{~ms}$ gives the temperature of the rear surface.

hand plot refers to a simulation with liquid motion. In this case, the melt layer remains fairly thin (no more than $25 \mu \mathrm{m}$ ), and appreciably more material is removed. The final ablation depth is about $100 \mu \mathrm{m}$. Thus in this case the inclusion of liquid motion in the model increases the material removal by about a factor of 4 .

The calculated temperature of the front edge (solid or liquid) exposed to the beam is shown in Fig. 5. This is shown for the case of liquid ejection. Responding to the sharp initial spike in the pulse, the temperature quickly rises to about $4300 \mathrm{C}$, and then drops to somewhat less than $2000 \mathrm{C}$. During the main body of the pulse, it rises to about $3600 \mathrm{C}$, then drops over a period of several hundred microseconds to the melting temperature $(1537 \mathrm{C}$, in this case). By the time of arrival of the next pulse, the temperature has decreased to about $145 \mathrm{C}$, corresponding to a net increase of $125 \mathrm{deg}$. Meanwhile, the temperature of the back edge has increased to about the same value. This is in accordance with 1-dimensional heat conduction, which is valid in steel on this scale of distances and times.

Now we turn to a series of experiments involving a single shot on a steel coupon. In this case, the diagnostics are the mass removal and the equilibrated coupon temperature. The shots have energies of about $500 \mathrm{~J}$ but different spot sizes, corresponding to fluences ranging from 155 to about $1100 \mathrm{~J} / \mathrm{cm}^{2}$. The coupon dimensions are $2 \times 2 \times 0.115 \mathrm{~cm}^{3}$. Figure 6 shows the measured mass removal $M$ as a function of fluence. For convenience, this has been divided by the spot area $A$. Thus if all the mass were assumed to be removed completely from the coupon, then the experimental $\mathrm{Q}^{*}$ would simply be $F /(M / A)$, with $F$ the fluence. Unfortunately, with data presently available, the fraction of removed mass leaving the coupon is not determined. It is certainly not true that all the liquid leaves, in view of the lips of frozen ejecta on the sides. 


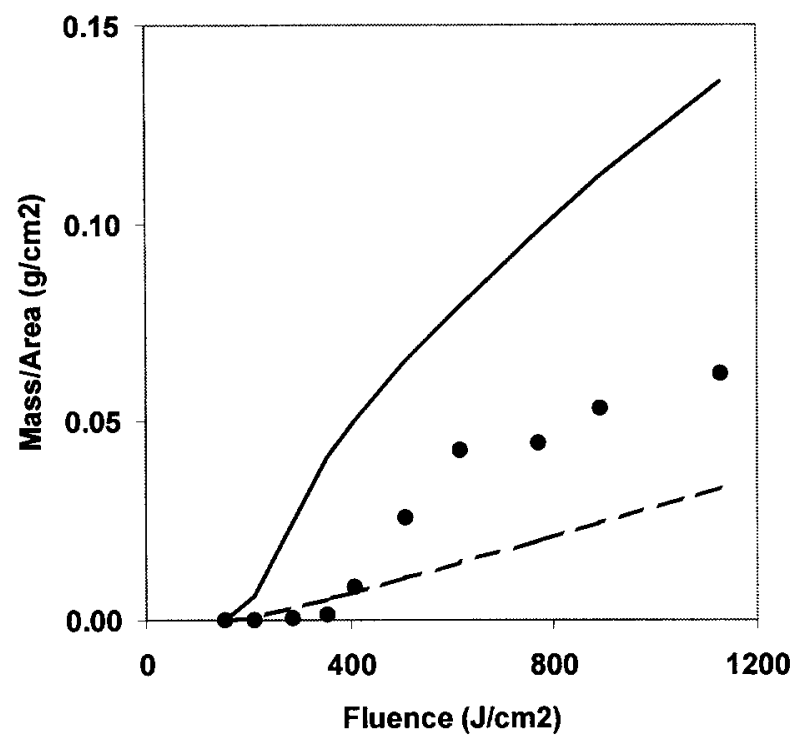

Fig. 6. Mass removal, per unit beam area, for a single pulse into a steel coupon, without air flow. The dots show data shots $020320 \mathrm{x}$ through $020320 \mathrm{ag}$. The solid line and dashed lines give the prediction for the cases of all ejected liquid assumed to leave the coupon or assumed to return to the coupon, respectively.

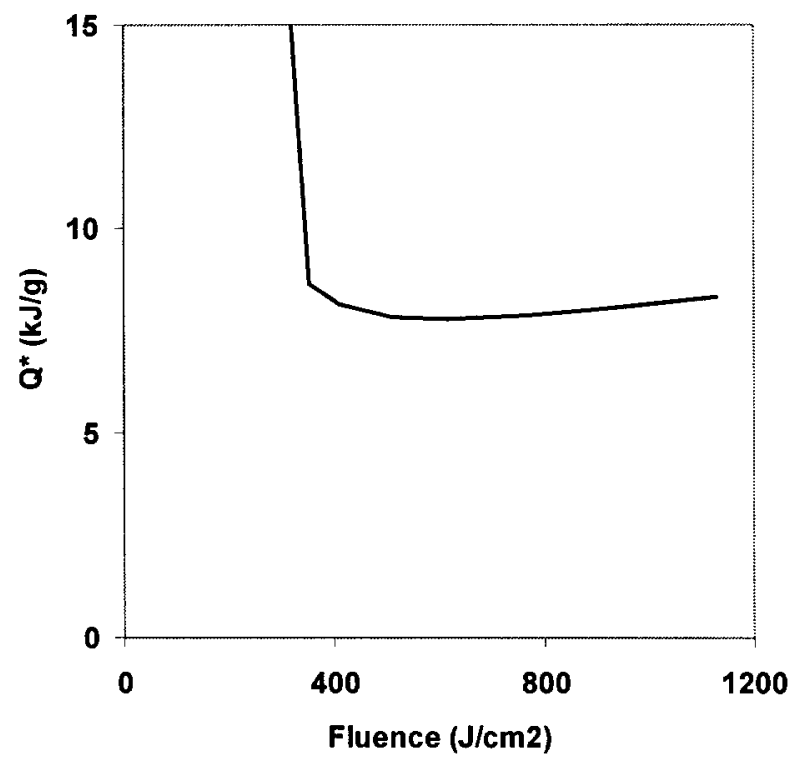

Fig. 7. Calculated Q* for the previous case. 


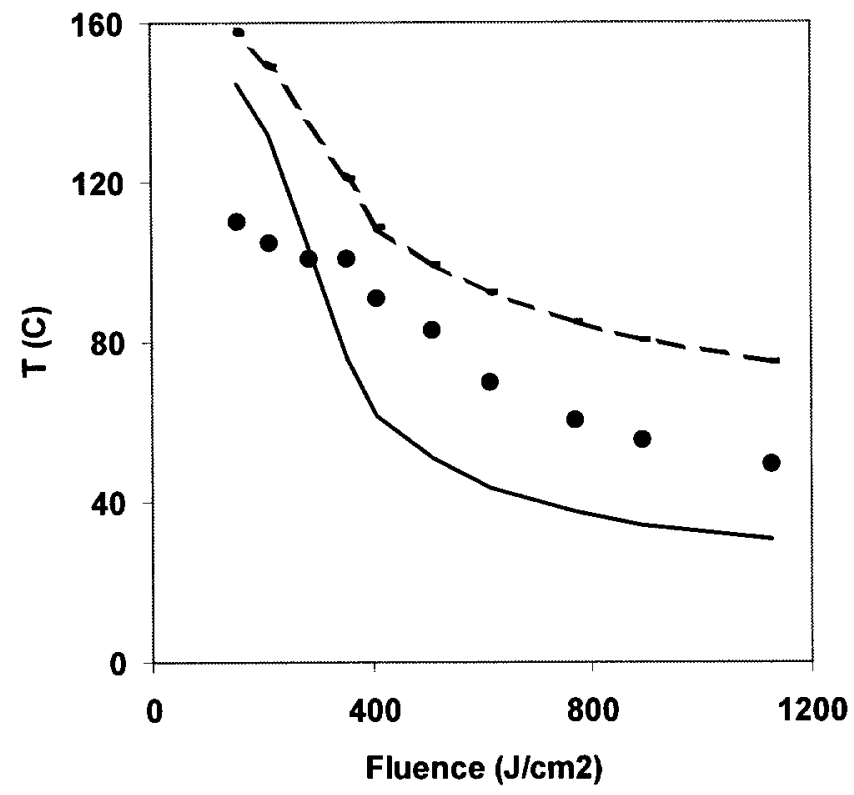

Fig. 8. Measured and calculated residual temperature of the coupon, for the same case as the previous two figures. The convention for solid and dashed lines is also the same.

The model predicts the hole depth but not the fraction of leaving or returning liquid ejecta. Thus Fig. 6 shows the predictions for the two cases of (1) all liquid leaving and (2) all liquid remaining. These bound the experimental results, as is appropriate. Since the actual hole depth is calculated by the model, a unique Q* can be calculated. As shown in Fig. 7, this has an extremely sharp decrease near the threshold for removal (about $300 \mathrm{~J} / \mathrm{cm}^{2}$ ), followed by a broad minimum near $7.8 \mathrm{~kJ} / \mathrm{g}$.

Figure 8 shows the measured equilibrated temperature versus fluence, along with the model predictions. It is interesting that the final temperature decreases as the fluence increases. The reason is that high-fluence shots invest more energy in removal. Similarly, the calculated residual temperature is lower when all liquid is assumed to leave the coupon. The calculations bound the data, except in the case of high residual temperatures. Here the data may be low because of experimental uncertainties.

Next we turn to experiments involving 1,2,3, or 4 successive pulses on a steel coupon. The diagnostics are again the mass removal and the coupon temperature. The energy per pulse, which gradually decreases with pulse number, is about $460 \mathrm{~J}$. The fluence per pulse is about $1500 \mathrm{~J} / \mathrm{cm}^{2}$. Figure 9 shows the mass removal as a function of number of pulses. Also shown is the residual temperature. Each of these increases almost linearly with pulse number. The calculations again pertain to the cases of all ejected liquid leaving the coupon or else remaining on it. These are consistent with the data, which fall about midway between the two bounds.

As noted, the model gives an unambiguous prediction of the hole depth (and volume, since the hole is calculated as a cylinder or rectangular prism), but it does not predict the final location of the ejected liquid. The available diagnostics, on the other hand, give the coupon mass loss but not the actual shape of the hole. Limited microscopic measurements of the hole shape have been made at LLNL. These have been applied to the case of a single shot on an aluminum coupon, with a beam energy in the range 

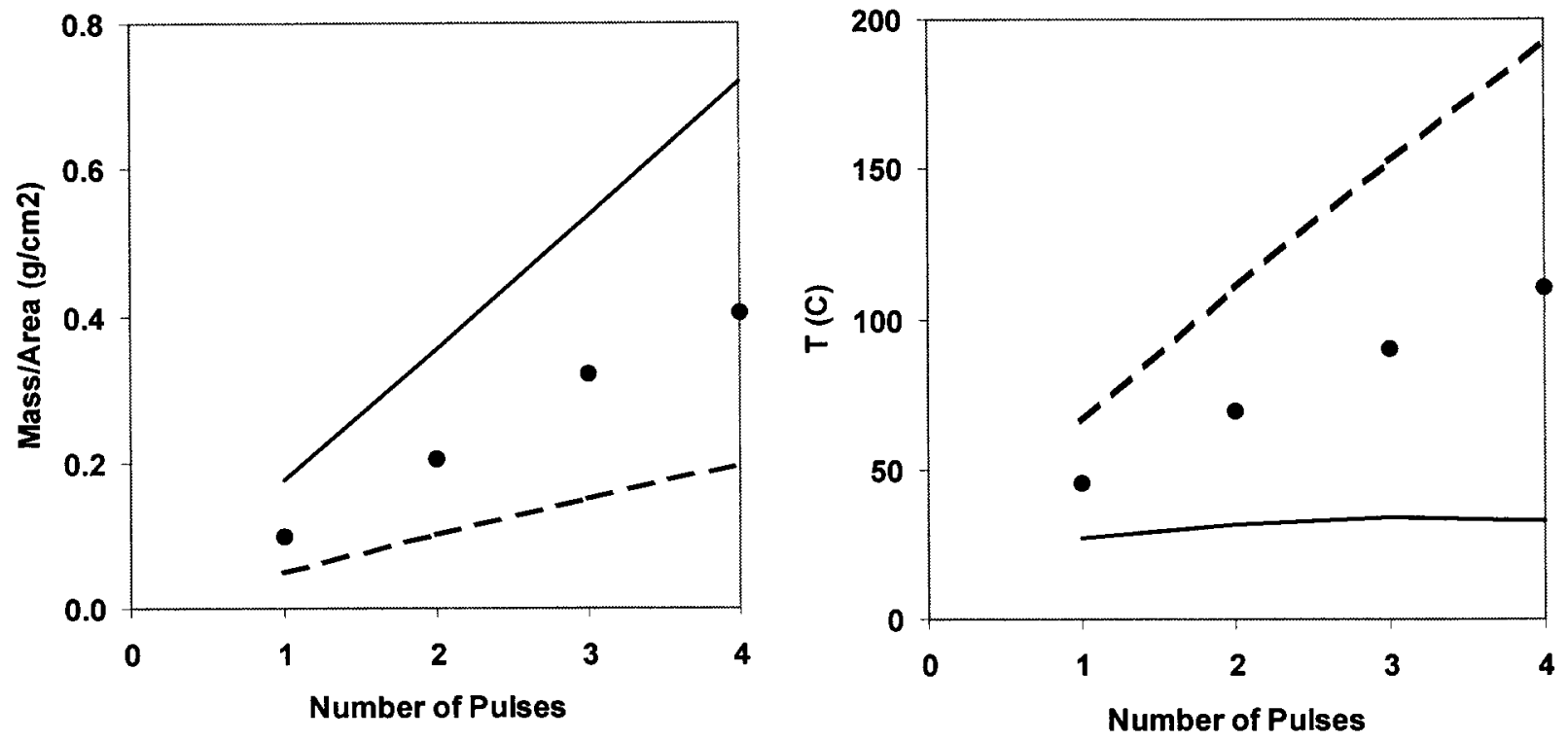

Fig. 9. Mass removal (per beam area) and residual temperature, for several shots on a steel coupon. The data correspond to shots $020423 \mathrm{c}$ through $020423 \mathrm{f}$. As before, the solid lines show the model prediction if all ejected liquid is assumed to leave the coupon. The dashed lines give the prediction if all ejected liquid is assumed to return to the coupon.

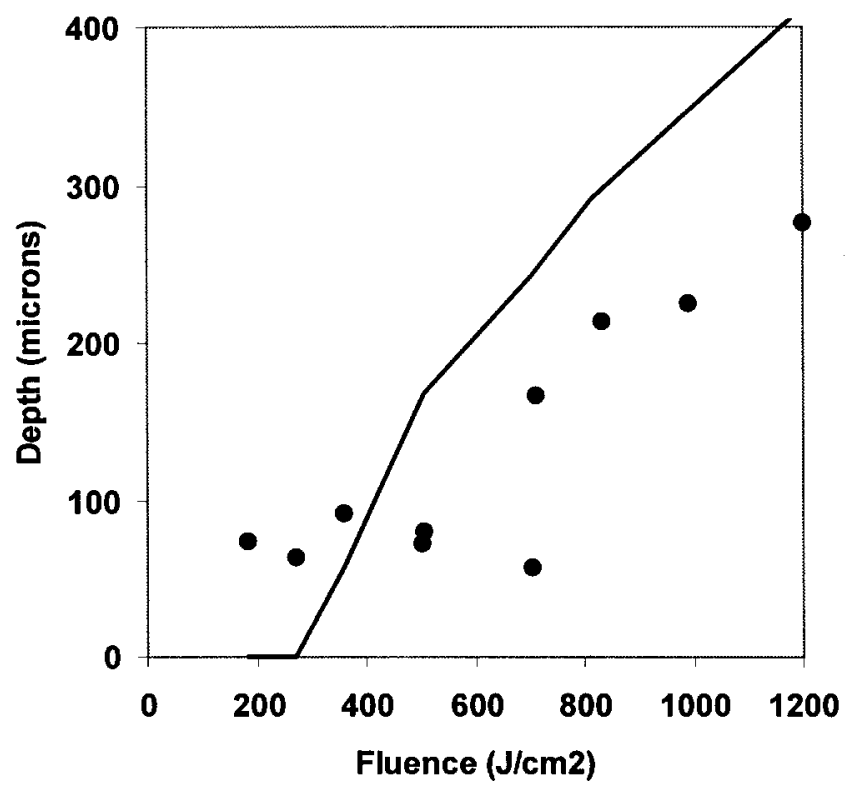

Fig. 10. Depth for single shots on an aluminum coupon, without air flow. The dots (shots $020319 \mathrm{~h}$ through $020319 q$ ) are measurements with a microscope. The line is the model prediction. 

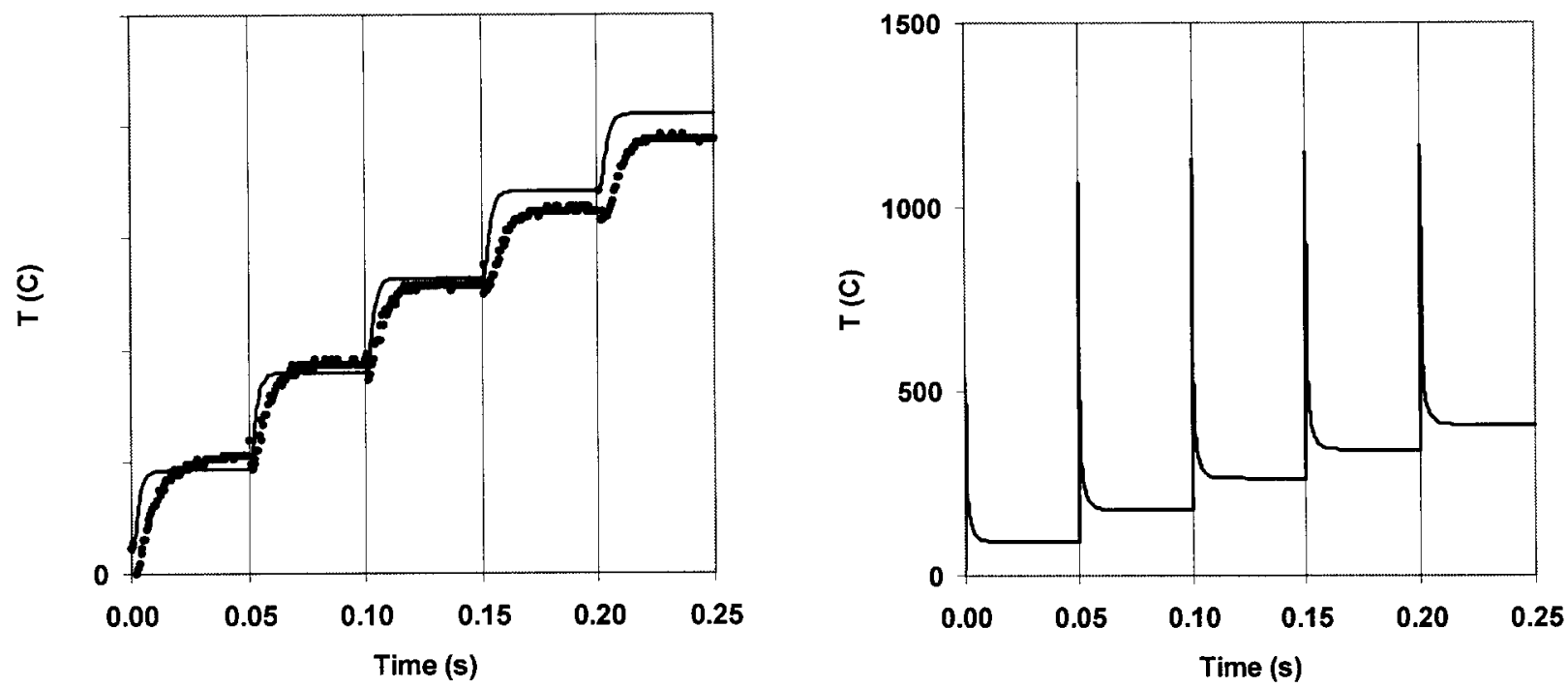

Fig. 11. Left: temperature of back surface of coupon, during 5 pulses on an aluminum coupon ( $500 \mathrm{~J}$ per pulse, spot size about $5 \mathrm{~cm}^{2}$ ). Right: calculated front surface temperature.

500-600 J. The spot size is varied to give a fluence ranging from 180 to $1200 \mathrm{~J} / \mathrm{cm}^{2}$. The results are shown in Fig. 10. These show a constant depth of about $100 \mu \mathrm{m}$ at low fluence $\left(200-400 \mathrm{~J} / \mathrm{cm}^{2}\right)$, followed by a gradual rise. Clearly the results at low fluence are not very precise, since other experience, such as visual observation and plume photographs, indicates a sharp threshold in fluence. This is also predicted by the model. With allowance for large error bars, the model appears consistent with experiment.

Now we consider an experiment giving the back face temperature during 5 successive pulses on an aluminum coupon. This is a large coupon, with dimensions 2 " $\times 5$ " $\times(1 / 16)$ ". The fluence per pulse is about $100 \mathrm{~J} / \mathrm{cm}^{2}$, resulting in essentially no material removal. As shown in Fig. 11, the temperature of the back surface rises quickly for about the first $10 \mathrm{~ms}$ of each pulse and then remains nearly constant during the remaining $40 \mathrm{~ms}$ until the arrival of the next pulse.

The model calculations match this behavior fairly consistently. The calculated temperature rises more quickly than experiment, perhaps because of an inaccuracy in the thermal conductivity. The temperature becomes constant in time, in accordance with the constraints of a 1-dimensional calculation without losses. During the fraction of a second after the 5th pulse (not shown), the back surface temperature relaxes due to lateral conduction. The calculated behavior of the front surface temperature is very different, as shown in Fig. 11. It is driven very rapidly to a high value (500-1000 C) during a pulse. This is followed by a decay to a temperature comparable to that of the back surface. The fact that the temperature ratchets up has an important and favorable bearing on the absorbed energy, as will be discussed below.

Because of its large thermal diffusivity, aluminum exhibits significant lateral heat conduction. For this reason, we requested a long-time 3-dimensional thermal calculation by L. Hagler (LLNL). No hydrodynamical effects were needed, or modeled. Figure 12 shows the calculated back surface temperature versus time. The long-time falloff caused by lateral conduction is given correctly. 


\section{Effects of air flow}

Air flow affects target interactions in a number of ways:

a) It removes small ejected droplets which shield the target.

b) It removes much of the melt layer.

c) It cools the target.

d) It supports target combustion.

e) It can break the target prior to melt-through.

All of these except for the third are favorable. We proceed to discuss them in turn.

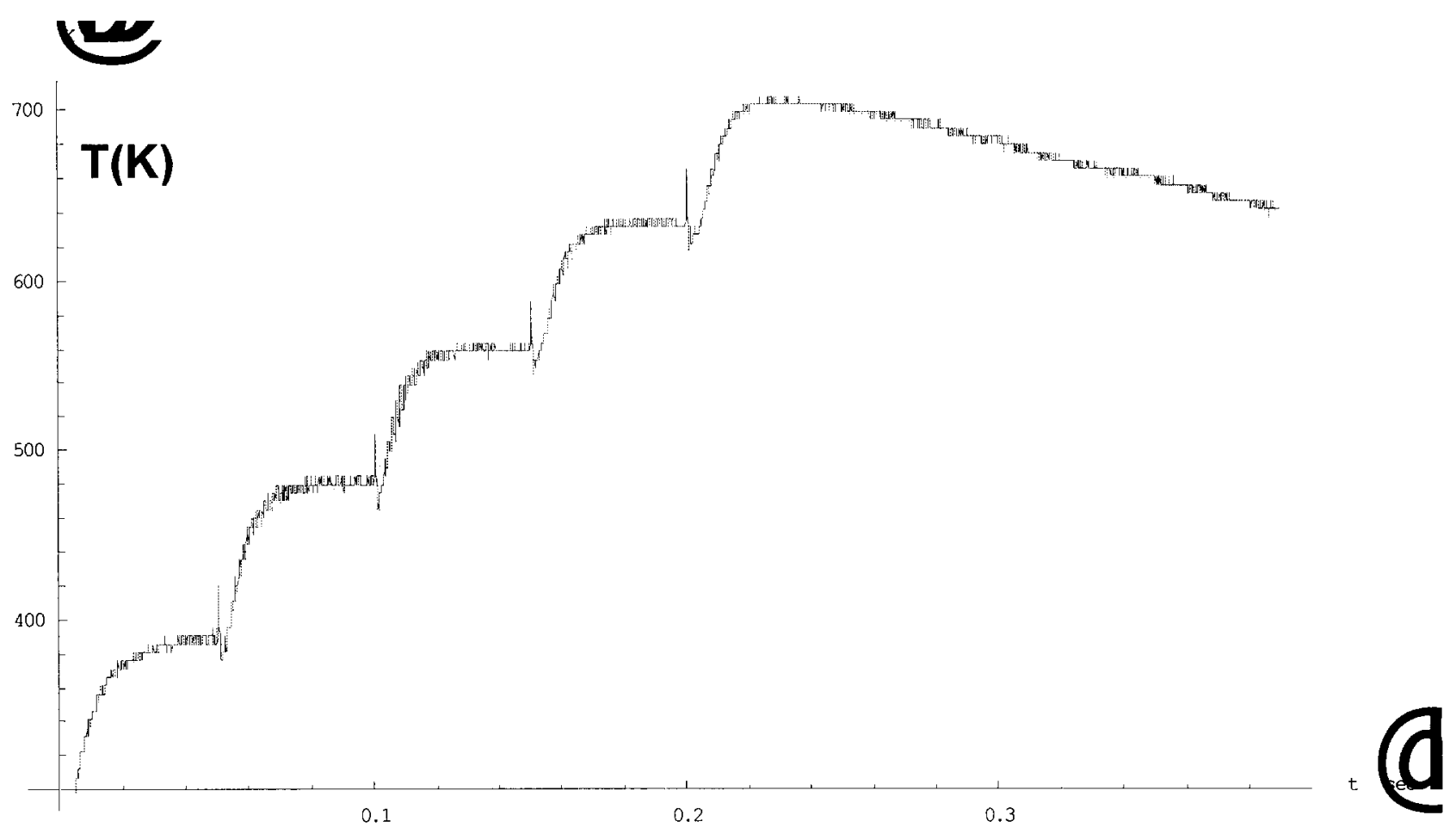

Time (s)

Fig. 12. Thin line: 3-dimensional ANSYS calculation of back surface temperature $(K)$ of an aluminum coupon. The experiment is the same as in the previous figure. The solid line indicates the data. 


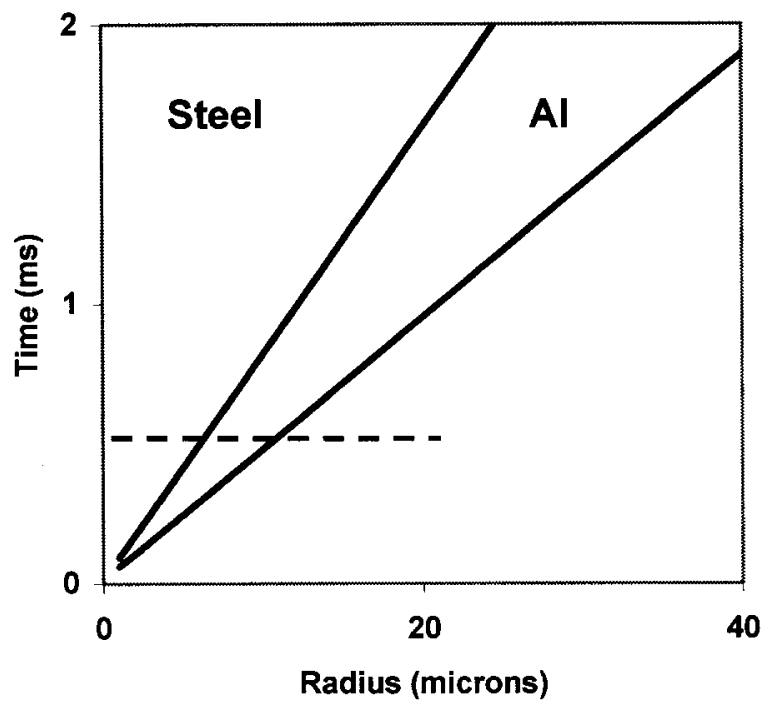

Fig. 13. Time required for wind at Mach 1 to remove a liquid particle from the beam, versus particle radius, for steel and air. The spot size is taken as $1 \mathrm{~cm}$. The dashed line gives a typical pulse duration.

\section{4(a) Removal of ejected droplets by air flow}

The motion of a liquid droplet parallel to the target is governed by Stokes' law,

$$
M \frac{d v}{d t}=6 \pi \eta_{a} r\left(u_{a}-v\right)
$$

in which the particle has radius $r$, mass $M=(4 / 3) \pi r^{3} \rho$, and parallel speed $v$. The air has parallel speed $u_{a}$ and viscosity $\eta_{a}$. From the solution of this equation, the distance moved within a time $t$ is

$$
x(t)=u_{a} \tau[t / \tau+\exp (-t / \tau)-1],
$$

where $\tau=(2 / 9) \rho r^{2} / \eta_{a}$ is a characteristic time. We have made the reasonable assumption that the initial parallel speed is much less than the wind speed. We are interested in the time to move a distance of the order of the spot size, say $a$. If this is appreciably less than the pulse duration, then the particle will have been removed from beam interactions.

There are two limiting cases, depending on whether the required time is much greater than, or much less than, the characteristic time $\tau$. In terms of particle size, this translates into whether the radius is much less than, or much greater than, respectively, a characteristic radius $r_{0}=\left(9 a \eta_{a} / 2 \rho u_{a}\right)^{1 / 2}$. For steel or aluminum in air at Mach 1 , this of order $1 \mu \mathrm{m}$. In the former case, the particle is sufficiently small to attain the wind speed almost immediately. The time required for removal from the beam is then just $a / u_{a}$. In the latter case, the particle is so sluggish that its speed can be neglected in comparison to the wind speed on the right-hand side of Stokes' law. Then its speed increases linearly with time, and the time required to move a distance $a$ is

$$
t=(2 r / 3)\left(a \rho / \eta_{a} u_{a}\right)^{1 / 2}
$$

This increases linearly with the particle size. 
The removal time is plotted as a function of particle radius, for a spot size of $1 \mathrm{~cm}$, in Fig. 13. The horizontal line denotes a sample pulse duration of $0.5 \mathrm{~ms}$. Reading the intercepts along this line, we see that the maximum diameter removed is $12 \mu \mathrm{m}$ for steel and $20 \mu \mathrm{m}$ for aluminum. It should be noted that the particle size cannot exceed the depth of the melt, which will be shown to have this same order of magnitude.

\section{4(b) Removal of melt layer by air flow}

The pattern of air flow near the target is extremely complicated, since a turbulent boundary layer exists. Hence the effect on the melt layer can be described only approximately.

First we consider the parallel component of the wind. From elementary considerations, the shear stress at the top of the melt layer must match the shear stress produced by the wind. The form of the latter has been established in wind tunnel experiments. Using this, we have a condition of the following form at the liquid surface (cf. Fig. 14)

$$
\eta \frac{\partial v_{x}}{\partial y}=f_{s} \rho_{a} u_{a}^{2}
$$

where $\eta$ is the liquid viscosity and $f_{s}$ is a skin friction factor. This factor is a slowly varying function of the Reynolds number of the air flow with respect to the spot size; it is of order 0.005 . Since the liquid velocity vanishes at the bottom of the melt layer $(y=0)$, an approximation to the profile induced by the shear condition is

$$
v_{x}(y)=f_{s} \rho_{a} u_{a}^{2} y / \eta
$$

The melt at a depth $y$ can be considered removed during a pulse time $\tau$ if $v_{x}(y)>a / \tau$, where $a$ is the spot size. Thus the maximum melt depth is approximately

$$
h_{\max } \approx \frac{a \eta}{f_{s} \rho_{a} u_{a}^{2} \tau},
$$

which is of order several tens of microns for our conditions. The actual depth would be expected to be less than this because of shear stress enhancement by surface modulations. In practice, we use a maximum depth of $30 \mu \mathrm{m}$ for steel. It should be noted that, at a shallow depth such as this, KelvinHelmholtz waves are strongly damped and cannot resonate with the wind.

Next we turn to the component of wind normal to the surface, which is important in nearly head-on engagements. This generates an additional pressure that can be estimated from gas kinetics. The pressure is of the order

$$
p=(1 / 2) \rho_{a} u_{a n}^{2},
$$

with $u_{a n}$ the normal component. For air of Mach 0.9 , this is about 0.6 bars.

Along the target surface, the momentum balance has the form

$$
\eta \frac{\partial^{2} v_{x}}{\partial y^{2}}=\frac{\partial p}{\partial x}
$$

as depicted in Fig. 15. The variation in pressure occurs above the heated region and has a characteristic length of the spot size $a$. For melt of depth $\mathrm{h}$, the parallel liquid speed at the surface is approximately

$$
v_{x} \approx \frac{h^{2} \rho_{a} u_{a n}^{2}}{6 \eta a},
$$




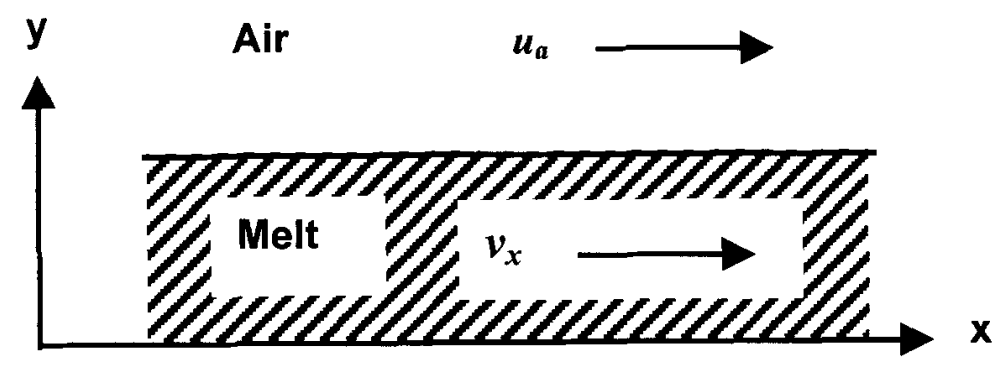

Fig. 14. Geometry of melt removal by the component of wind parallel to the target surface.

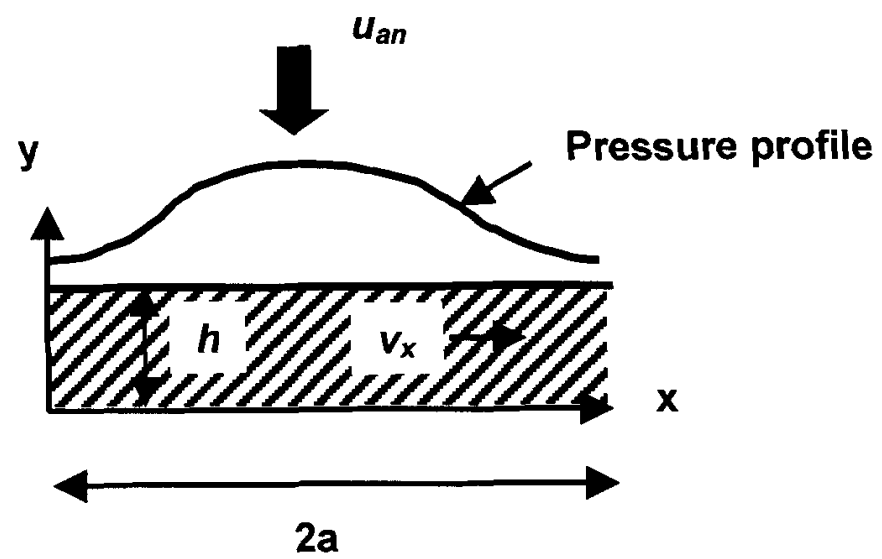

Fig. 15. Geometry of melt removal by the normal component of the wind.

with the factor of 6 roughly accounting for profile effects. This velocity results in melt removal. For Mach 0.9 air blowing on a $1-\mathrm{cm}$ spot of depth $100 \mu \mathrm{m}$, the melt removal time is about $1 \mathrm{~ms}$. Vortices in the wind will enhance the melt removal, by increasing the local pressure gradients. Melt removal by the parallel component of the wind is accounted for in an approximate manner in the model. Removal by the perpendicular component has not yet been implemented.

\section{4(c) Cooling by air flow}

Again we are dealing with a turbulent air boundary layer, so the considerations are necessarily qualitative. The cooling rate due to the wind is proportional to the difference in surface temperature and air temperature:

$$
Q=\gamma\left(T-T_{a}\right),
$$




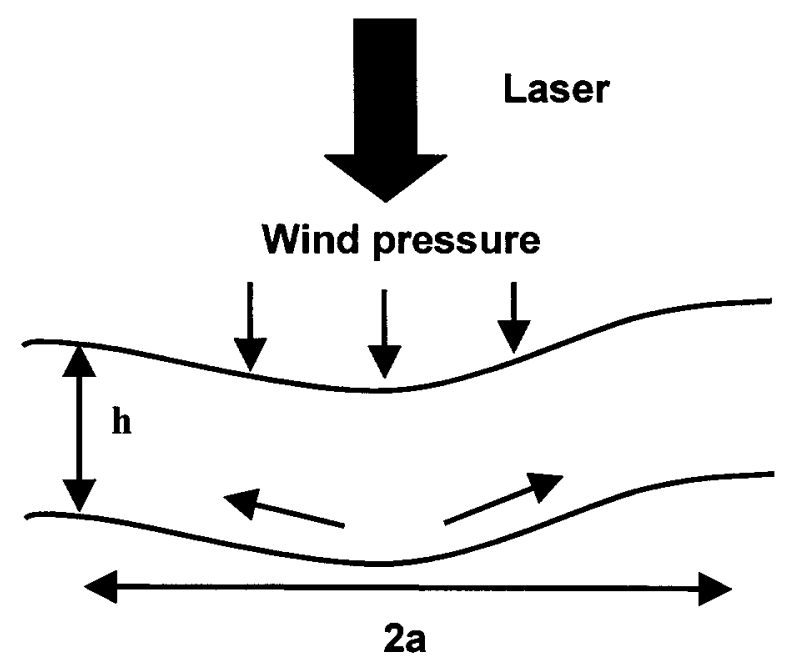

Fig. 16. Breaking of target by wind pressure.

with the heat transfer coefficient $\gamma$ depending on details of the boundary layer. Wind tunnel experiments give an expression of the form

$$
\gamma=\beta(\operatorname{Re}) \rho_{a} C_{p a} u_{a},
$$

which equals about $0.16 \mathrm{~W} /\left(\mathrm{cm}^{2} \mathrm{~K}\right)$ for Mach 1 air past a spot size of $1 \mathrm{~cm}$. Thus if the surface temperature is $2000 \mathrm{C}$, the resulting cooling rate is about $0.3 \mathrm{~kW} / \mathrm{cm}^{2}$. This is inconsequential during a pulse, but it can be significant between pulses. This treatment has been implemented in the model.

\section{4(d) Target combustion}

Air can support exothermic reactions in steel and aluminum, leading to a dramatic increase in target damage. We defer the discussion of this important effect to the experimental analysis in Section 5. The effect has not yet been implemented in the computational model.

\section{4(e) Breaking of the target prior to melt-through}

The additional pressure $p$ from the normal component of wind can break the target before melt-through. For typical targets with a thin metallic skin of thickness $h$, the back of the skin will be put into tension by pressure on the front (Fig. 16). The important point is that the tensile stress on the back scales with the spot aspect ratio as $T \sim p(a / h)^{2}$. For a spot size of $1 \mathrm{~cm}$ and a thickness of $1 \mathrm{~mm}$, the stress intensification factor is 100 . This increases with material removal. The drop in material strength with temperature can then produce breaking before melt-through. Stainless steel, for example, has a tensile strength of about 100 bars at $1000 \mathrm{C}$. This important effect has not yet been implemented in the computational model.

\section{Comparison with experiments involving air flow}

We now turn to HELSTF experiments with flow past the face of the coupon at Mach 0.9. First we consider single pulses, having approximate energy $500 \mathrm{~J}$ but various spot sizes, on a steel coupon. The resulting fluence is in the range $140-2000 \mathrm{~J} / \mathrm{cm}^{2}$. The mass loss measurements, along with the calculated 


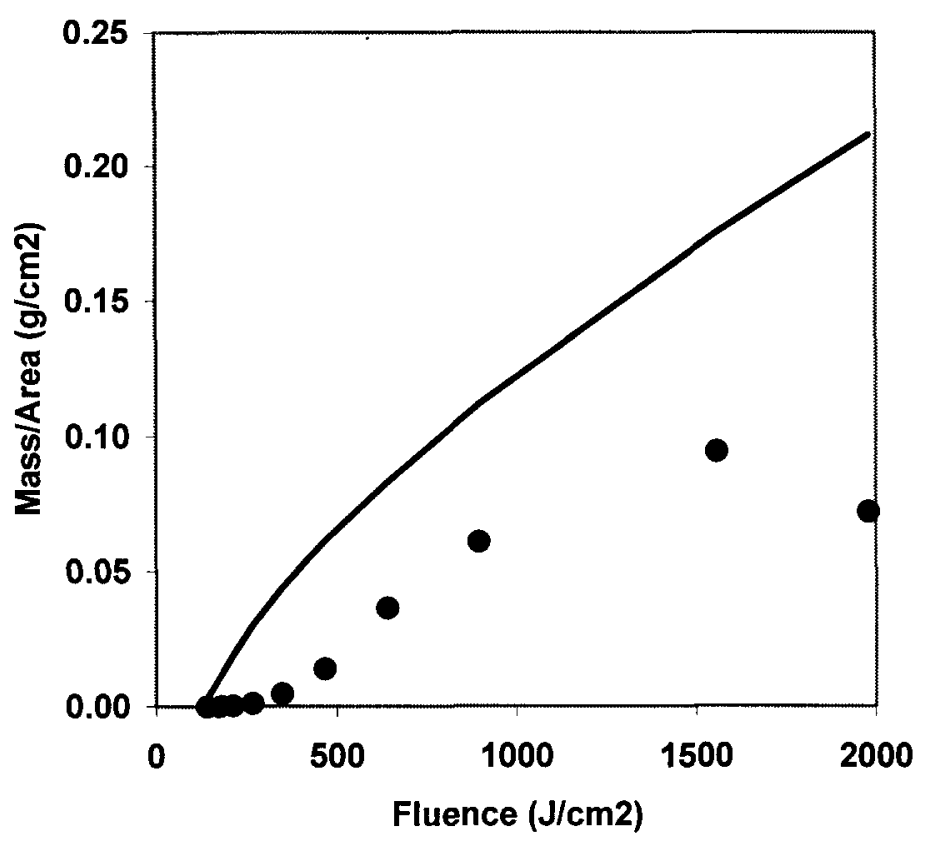

Fig. 17. Mass loss per area for a single pulse, with various spot sizes, on a steel coupon. Air flow at Mach 0.9 is present. The dots are shots $020515 \mathrm{~d}-020515 \mathrm{v}$. The point at $2000 \mathrm{~J} / \mathrm{cm}^{2}$ would appear to be spurious. The line is the model prediction.

predictions, are shown in Fig. 17. The calculations assume that all liquid is removed. They have about the right threshold overestimate the mass removal, as would be expected, since some melt is observed to freeze downwind on the coupon. As before, the definitive comparison will involve microscopic measurements of the holes, which are just beginning.

Next we turn to a melt-through experiment (run 02050101). With a steel coupon of nominal thickness $1 / 16$ " and a spot size of $1.32 \mathrm{~cm}^{2}$, melt-through was observed after 15 pulses. The pulse energy, which dropped by a few joules per pulse, averaged to about $465 \mathrm{~J}$, for a typical fluence of about $350 \mathrm{~J} / \mathrm{cm}^{2}$. The modeling (cf. Fig. 18) gives melt-through during pulse 12. As seen in the figure, the temperature of the rear face jumps markedly during the last few pulses. The reason is that the coupon width is narrowing. Note also that, for the first 8 pulses, the rear face temperature tends to become constant in time before the next pulse, as expected in a 1-dimensional calculation with insignificant losses. During the last few pulses, however, the coupon has become sufficiently thin that air cooling of the front face affects the rear face temperature. This is the reason for the steady decline following pulses 9 through 11 .

In the next experiment, a steel coupon is exposed to 5 pulses at a fluence of $100 \mathrm{~J} / \mathrm{cm}^{2}$ per pulse $(500 \mathrm{~J}$ on $5 \mathrm{~cm}^{2}$ ). The experiment is performed both with and without nitrogen flow at Mach 0.9 . The temperature of the rear face during the first second is shown in Fig. 19. At this low fluence, it is clear that gas flow has a net cooling effect. There is essentially no melt for the gas to remove. The model predictions tend to agree with experiment during the pulses (first $25 \mathrm{~ms}$ ). The model gives a constant long-time temperature, in the absence of gas flow. As noted, this is appropriate for a $1 \mathrm{D}$ calculation because of the absence of 

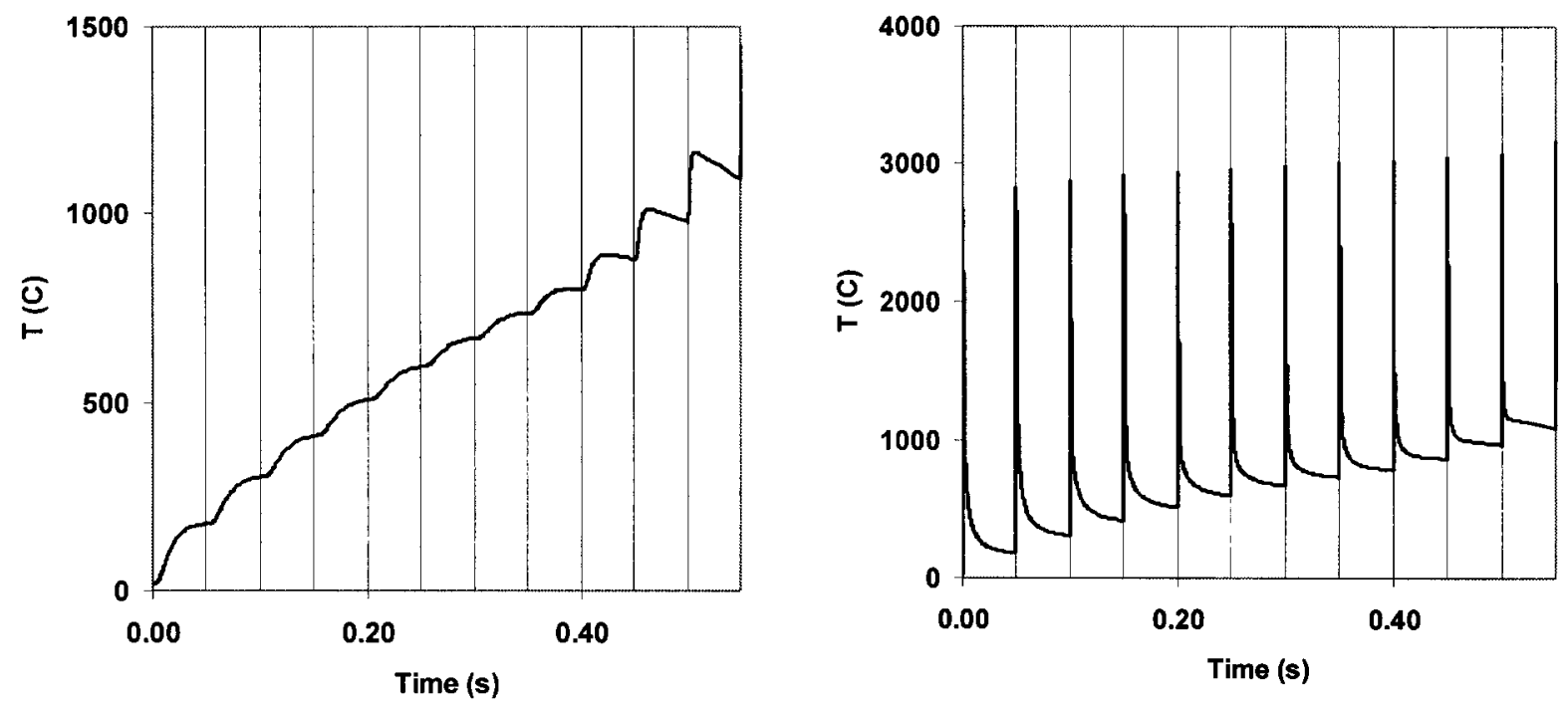

Fig. 18. Calculated temperatures of the rear face (left) and front face (right) of a steel coupon exposed to 12 pulses, with air flow. Melt-through occurs during the last pulse (not shown completely).

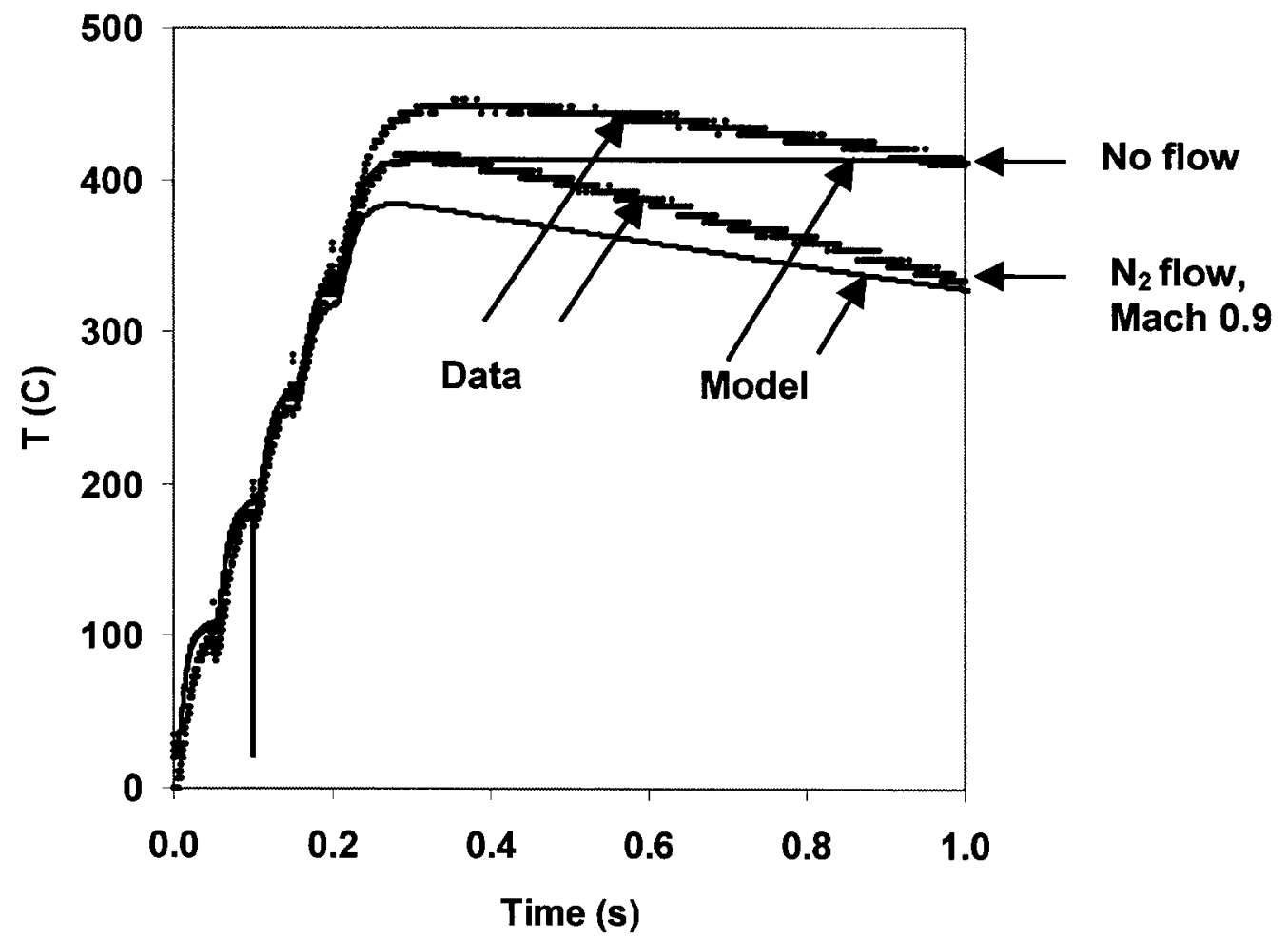

Fig. 19. Rear face temperature of a steel coupon exposed to 5 pulses $\left(100 \mathrm{~J} / \mathrm{cm}^{2}\right.$ per pulse), both with and without nitrogen flow. 


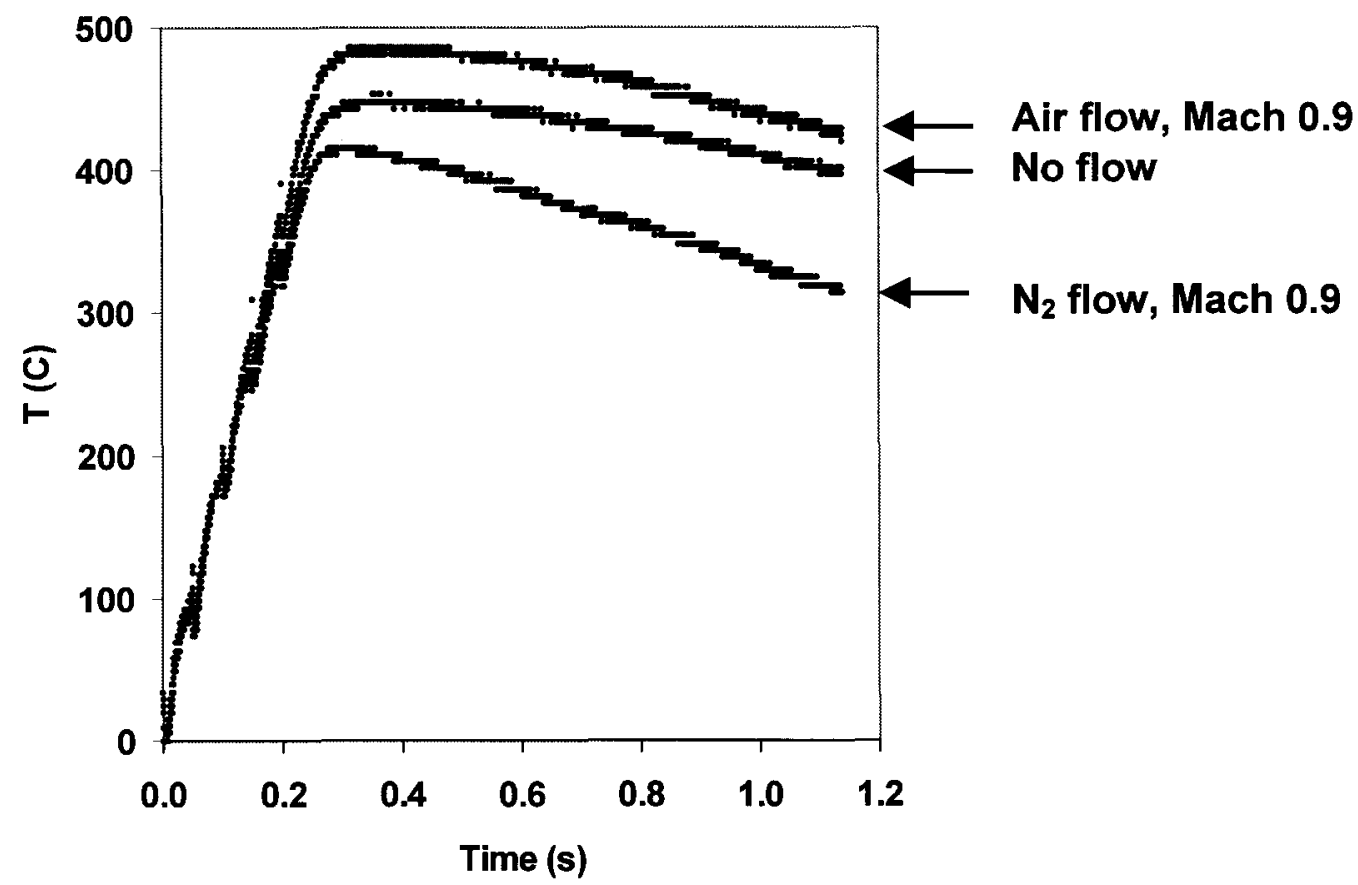

Fig. 20. Rear face temperature of a steel coupon exposed to 5 pulses $\left(100 \mathrm{~J} / \mathrm{cm}^{2}\right.$ per pulse), with air flow, with nitrogen flow, and with no flow.

lateral conduction. In the presence of flow, the model gives a steady drop in temperature, with a rate somewhat less than that of experiment. This is just as expected.

There is good reason to believe, therefore, that the model gives a reasonable accounting for the effects of flow parallel to the surface.

The important process of combustion is indicated in the next figure (20), which shows the same situation as in the previous figure with the addition of air flow, as opposed to nitrogen flow. With air flow, the temperature increases relative to that with nitrogen flow, with the increase being about $100 \mathrm{deg}$ in this case. This indicates an exothermic reaction such as combustion. In iron, there are three such reactions, with formation energies in the neighborhood of $50 \mathrm{kcal} / \mathrm{mole}$ for our range of temperatures. Given the temperature rise, this corresponds to an oxidized layer of about $30 \mu \mathrm{m}$, which may be a low estimate. Chemical analysis of the coupons would be of great interest.

\section{Importance of material properties}

The calculations employ a number of material properties. Some of these, such as the heat of fusion, are well established. Others, such as the heat capacity and thermal conductivity, are known with modest accuracy in the solid phase but are much less available in the liquid phase. Since the physical processes in a solid and liquid are different, a jump can occur at the melting point. The calculations in this report require the material properties, as functions of temperature, well into the liquid phase. Those used for steel (modeled as pure Fe) are shown in Fig. 21. The peak in the specific heat [8] at $770 \mathrm{C}$ corresponds to the Curie transition. We assume a constant value in the liquid, which could certainly be improved. The thermal conductivity values, taken from [9], are "extrapolated or estimated" in the liquid. 

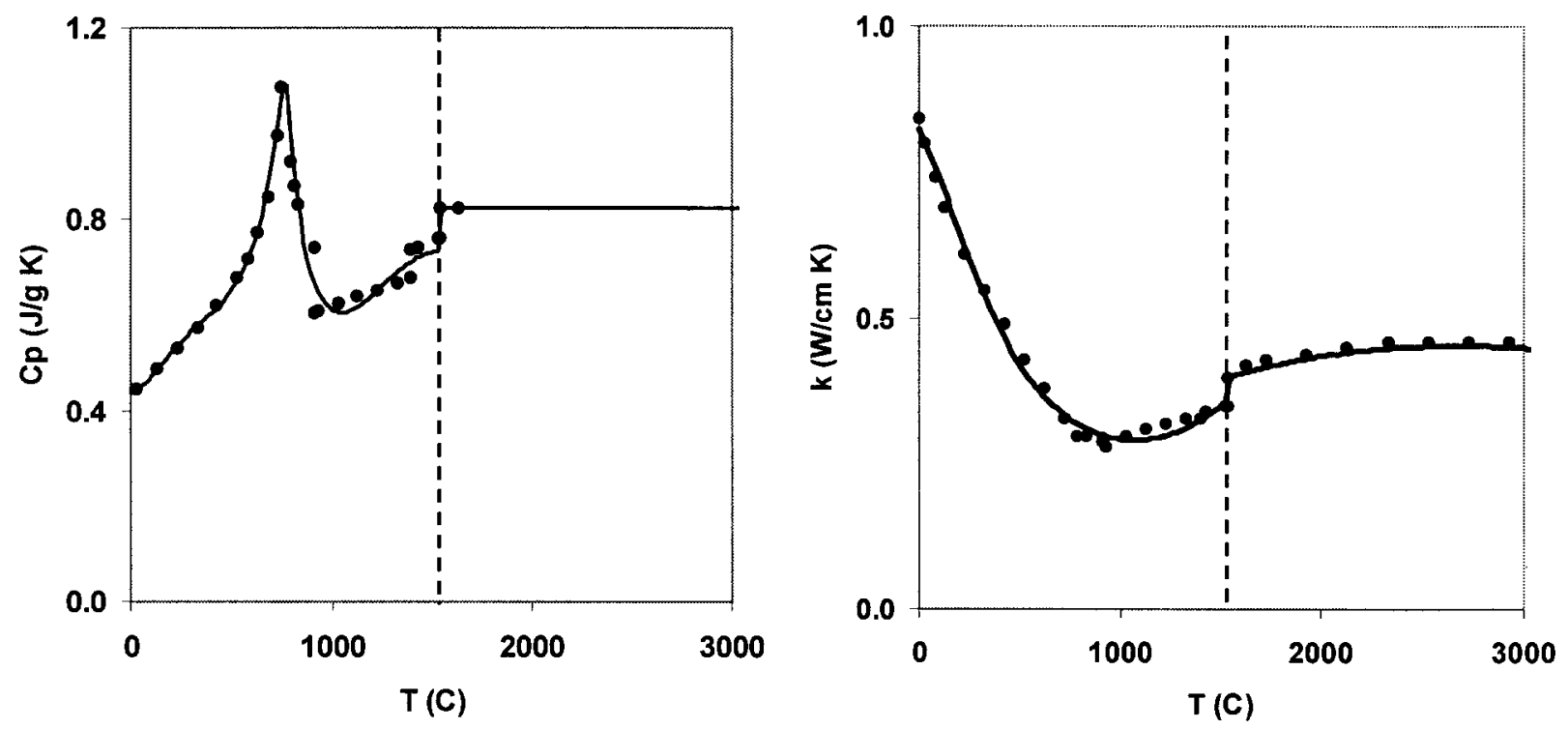

Fig. 21. Specific heat and thermal conductivity of steel used in the model. The latent heat of melting is not depicted. The dotted line signifies the melting point.

A crucial, and very poorly known, material property required by the model is the optical absorptivity. This depends on temperature and wavelength (and for oblique incidence, the polarization). In metals, it is a strong function of surface conditions, since the skin depth is of order several $\mathrm{nm}$ for wavelengths near a micron. The value for a pristine surface at room temperature, commonly found in references, is of little interest here. Because scattering increases with temperature, the absorptivity of a pure metal is also expected to increase with temperature. The literature contains assorted values of uncertain accuracy. For our purposes, we used simple curves (Fig. 22) adjusted so that coupon temperature measurements such as those in Fig. 11 would come out with reasonable accuracy. Obviously, this process does not uniquely determine the temperature dependence.

The most ambitious absorptivity measurements of which we are aware were performed at AFRL [10] with an integrating sphere technique. Those of interest here (cf. Fig. 22) pertain to SS-304 and Al-2024, for temperatures well below the melting point. Below about $600 \mathrm{C}$, the stainless steel measurements are consistent with the curve used here. Thereafter, the measured values increase by more than a factor of 2 over a range of $150 \mathrm{deg}$. We elected not to use this portion of the data, hypothesizing that it might be due to the substantial chromium and nickel content of stainless steel. Similarly, the points in aluminum are consistent (within 10\%) with the curve used here. It would be of great interest for measurements like these to be applied to the particular materials of interest and to be extended to higher temperatures.

\section{Advantage of pulsed lasers over $\mathrm{CW}$ lasers}

The fact that the absorptivity is believed to increase with temperature points to an advantage for pulsed operation. It allows increased absorption, since the front surface temperature is periodically brought to a higher value than in the $\mathrm{CW}$ case. 

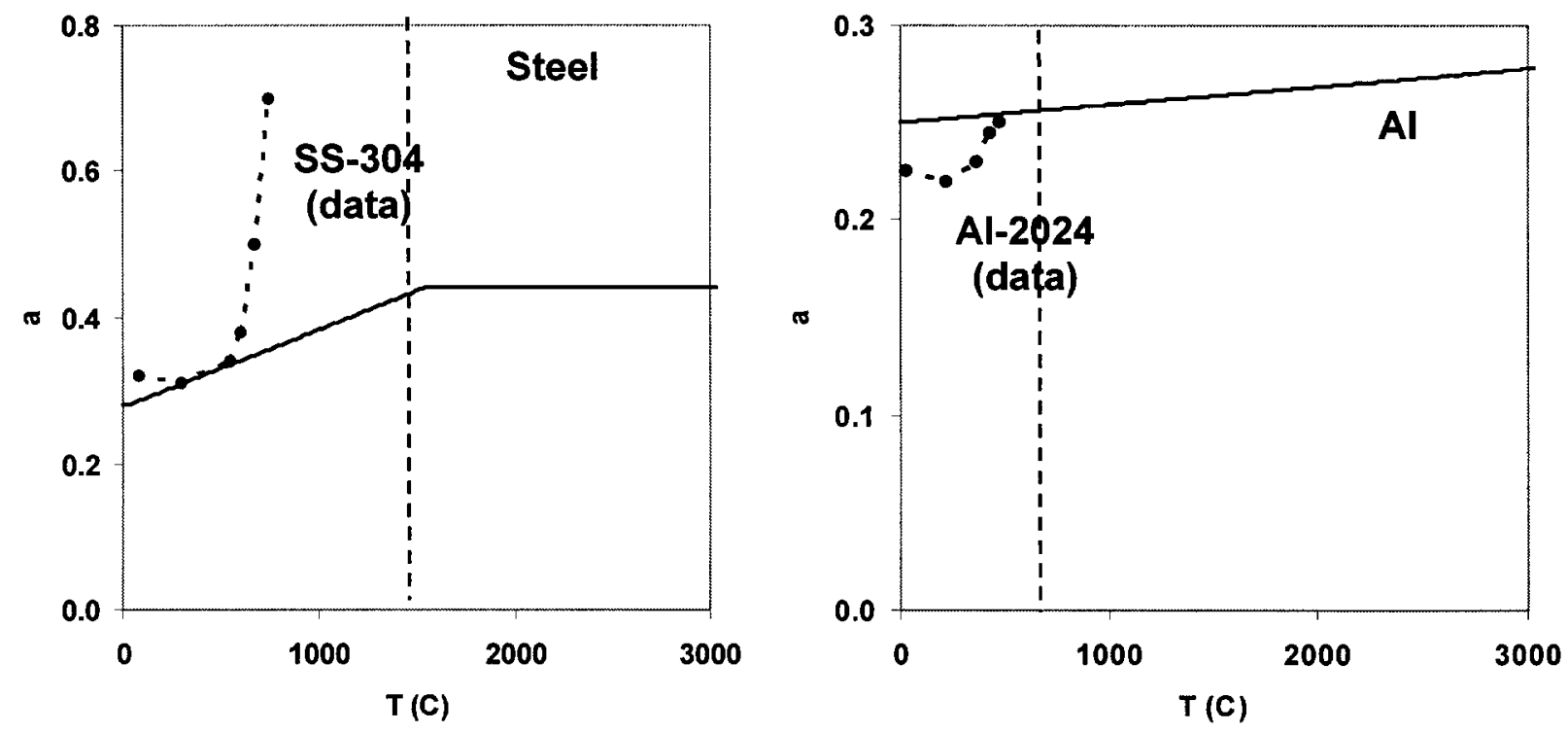

Fig. 22. Absorptivity of steel and aluminum used here (solid lines), along with measurements from [10]. These pertain to normal incidence.

In Fig. 23, we show predictions for the exposure of a steel foil (spot size $5 \mathrm{~cm}^{2}$, thickness $0.2 \mathrm{~cm}$ ) to $10 \mathrm{~kW}$ for $0.5 \mathrm{~s}$, for both pulsed and CW cases. In the SSHCL case, this amounts to 10 pulses of $500 \mathrm{~J}$, at $20 \mathrm{~Hz}$. As expected, the temperature of the front surface periodically peaks (in this case, at values somewhat above the melting temperature), followed by a slow decay. In the $\mathrm{CW}$ case, on the other hand, the temperature necessarily builds up gradually. The pulsed temperature always exceeds the $\mathrm{CW}$ temperature, except for a short interval near the end of the first pulse. Because the absorptivity is sampled at higher values in the former case, more energy is absorbed. This is reflected in the rear face temperature (bottom plot), which becomes $170 \mathrm{deg}$ hotter in the pulsed case (580 C as opposed to $410 \mathrm{C}$ ).

This calculation is intended to be illustrative of the effect of increased absorptivity. The temperature is overestimated in the $\mathrm{CW}$ case, since the wavelength has been taken as $1 \mu \mathrm{m}$. The absorptivity is expected to be lower at longer wavelengths ( $1.3 \mu \mathrm{m}$ for COIL, $3.8 \mu \mathrm{m}$ for DF). Thus the regime can be further optimized.

\section{Conclusions and recommendations}

We have developed a model of material interactions in the regime accessed by SSHCLs. The model describes heat conduction, melting, liquid hydrodynamics, and vapor hydrodynamics. Some important air flow effects, such as melt removal and convective cooling, have also been included.

The model has been used to analyze a number of experiments performed with the $10 \mathrm{~kW}$ SSHCL at HELSTF. Comparisons have been made with the coupon mass loss, the residual temperature, the hole depth, temperature traces, and melt-through times - both with and without air flow. All indications suggest that the model is generally consistent with experiment. More precise tests would involve 

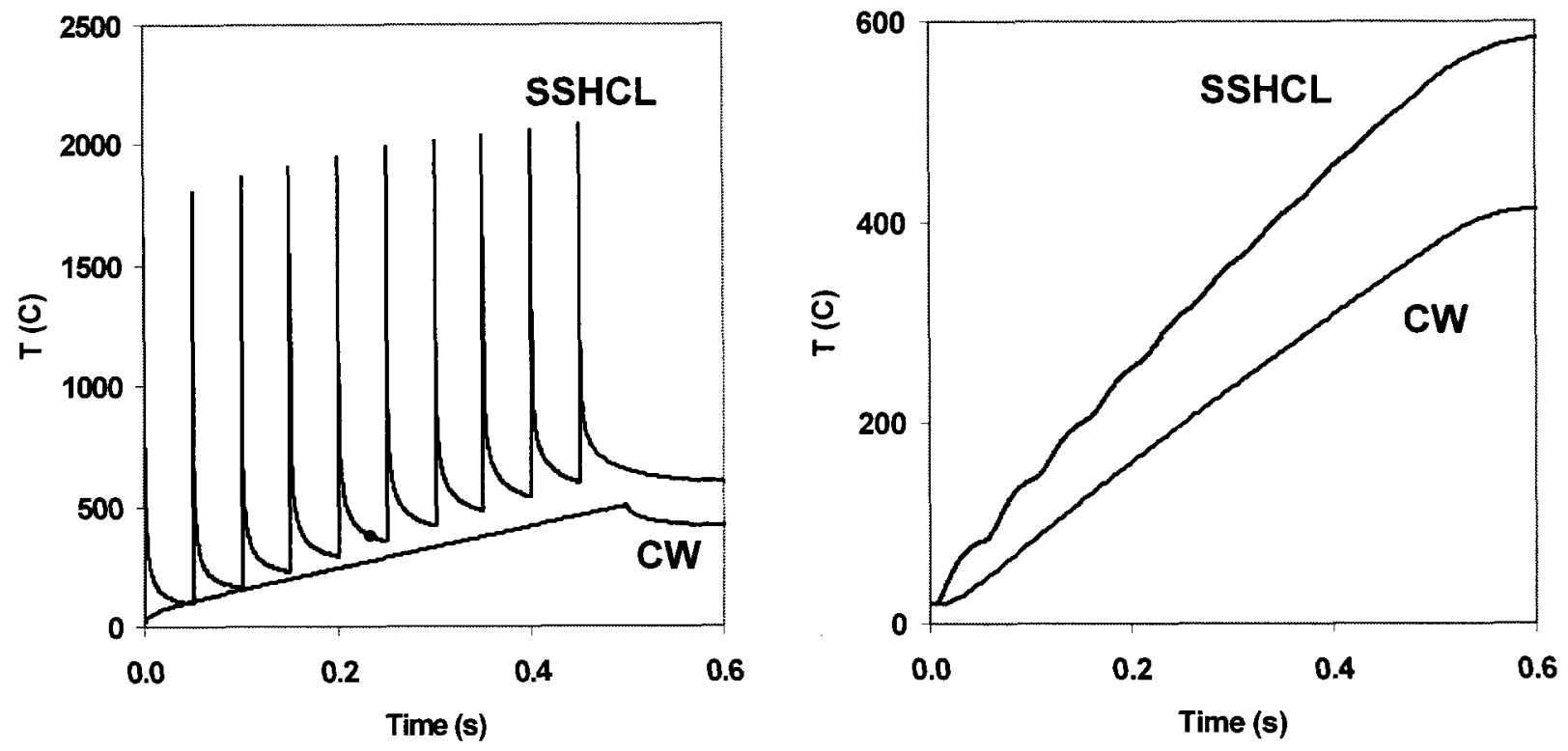

Fig. 23. Calculated temperatures of front surface (left) and back surface (right) of a steel foil exposed to $10 \mathrm{~kW}$ for $0.5 \mathrm{~s}$ by a SSHCL and a CW laser.

systematic measurements of the hole profile. In cases with discrepancies, agreement might be increased by a more accurate materials database.

We have identified three favorable effects which deserve further exploration. These are:

(1) Combustion in the target,

(2) Breaking of the target before melt-through, when the temperature-dependent tensile stress limit is exceeded,

(3) More efficient deposition of heat by pulsed lasers than cw lasers, because of the increase of material absorptivity with temperature.

Much can be learned from further coupon experiments with air flow. We have predicted effects associated with the perpendicular wind (additional melt removal, and target breaking) which should be explored. Finally, much more attention should be devoted to the materials database. In particular, the absorptivity of materials of interest should be determined well into the liquid phase.

\section{Acknowledgments}

We are happy to thank C. B. Dane for discussions and for his continuing interest. We are grateful to S. N. Fochs for providing the data.

This work was supported by the U.S. Army Space and Missile Defense Command. The work was performed under the auspices of the U.S. Department of Energy by the University of California, Lawrence Livermore National Laboratory, under Contract No. W-7405-ENG-48. 


\section{References}

[1] C. D. Boley and J. T. Early, "Computational Model of Drilling with High Radiance Pulsed Lasers," Proc. Intern. Conf. on Applications of Lasers and Electro-Optics, Orlando, FL, Vol. 79, p. 499 (1994); SPIE Vol. 2500 (1994).

[2] M. A. Norton, C. D. Boley, J. E. Murray, K. Sinz, and K. Neeb, "Long-Lifetime, Low-Contamination Metal Beam Dumps for NIF Spatial Filters," Third Inter. Conf. on Solid State Lasers for Application to Inertial Confinement Fusion, SPIE Vol. 3492, pp. $901-911$ (1999).

[3] C. D. Boley, C. B. Dane, and E. A. Stappaerts, "Material Removal by a Heat Capacity Laser," Laser Science and Technology Annual Report - 2001, Lawrence Livermore National Laboratory, UCRL-ID134972-01, March 2002.

[4] C. D. Boley and A. M. Rubenchik, "Modeling of Material Removal by Solid State Heat Capacity Lasers, Proc. 15th Annual Solid State and Diode Laser Technology Review, Albuquerque, NM, June 3-6, 2002.

[5] C. D. Boley and A. M. Rubenchik, "Modeling of Material Effects Produced by a Solid State Heat Capacity Laser," High Energy Pulsed Laser Lethality Effects and Beam Propagation Workshop, U.S. Army Space and Missile Defense Command, Huntsville, AL, Aug. 27-28, 2002.

[6] S. I. Anisimov, "Vaporization of Metal Absorbing Laser Radiation," Sov. Phys. JETP 27, 182-183 (1968); C. J. Knight, "Theoretical Modeling of Rapid Surface Vaporization with Back Pressure," AIAA J. 17, 519-523 (1979).

[7] C. S. Yih, "Fluid Mechanics of Colliding Plates," Phys. Fluids 17, 1936-1940 (1974).

[8] R. Hultgren et al., "Selected Values of the Thermodynamic Properties of the Elements," American Society for Metals (1973), p. 185.

[9] Y. S. Touloukian et al., "Thermophysical Properties of Matter," Vol. 1, Thermal Conductivity, Metallic Elements and Alloys, IFI/Plenum, NY (1970), p. 169.

[10] J. E. Beraun, "Temperature-Dependent Reflectance of Aero-Space Materials (TRAM)," AFRL/DELE (presentation). 